\title{
The Effect of Different Diet on Saliva
}

\section{Vladimíra Tomečková1 ${ }^{*}$, Kristína Krajčíková1, Slavomíra Dolinská1, Vladimír Komanický2, Tomáš Samuely ${ }^{2}$}

${ }^{1}$ Department of Medical and Clinical Biochemistry, Faculty of Medicine, Pavol Jozef Šafárik University in Košice, Košice, Slovak Republic

${ }^{2}$ Institute of Physics, Faculty of Science, Pavol Jozef Šafárik University in Košice, Košice, Slovak Republic

Email: *vladimira.tomeckova@upjs.sk, kristina.ugrayova@student.upjs.sk, slavomira.dolinska@student.upjs.sk,

vladimir.komanicky@upjs.sk

How to cite this paper: Tomečková, V., Krajčíková, K., Dolinská, S., Komanický, V. and Samuely, T. (2017) The Effect of Different Diet on Saliva. Spectral Analysis Reviews, 5, 37-48.

https://doi.org/10.4236/sar.2017.54004

Received: June 19, 2017

Accepted: September 17, 2017

Published: September 21, 2017

Copyright $\odot 2017$ by authors and Scientific Research Publishing Inc. This work is licensed under the Creative Commons Attribution International License (CC BY 4.0).

http://creativecommons.org/licenses/by/4.0/

\begin{abstract}
The aim of this scientific research was to study the influence of various diets (ketogenic, low carb, mixed) on teeth and saliva structure of healthy individuals. The health condition of teeth and the influence of diet (sweets, water intake) were investigated using the questionnaires which were statistically processed by descriptive and inductive statistics. Saliva was examined using synchronous fluorescent fingerprint (SFF) and atomic force microscopy (AFM). The statistical evaluation of answers of respondents using the questionnaires about intake of sweets in their diet showed significant influence of sugars on formation of tooth decay of diet. The intake of water (volume and frequency) did not show significant influence on formation of tooth decay. Endogenous fluorescence and surface structure of saliva differed in healthy subjects with different diet. The most organized surface structure showed low carb diet (without crystals). The least organized surface structure showed ketogenic diet with the big crystals $(1-2 \mu \mathrm{m})$. Untraditional methods (SFF and AFM) enable the new, sensitive and quick analysis of the mixture of saliva. Saliva of individuals with low carb diet showed the most organized structure. Low content of sugar in diet is important possibility of the prevention before dental carries.
\end{abstract}

\section{Keywords}

Low Carb Diet, Mixed Diet, Ketogenic Diet, Saliva, Synchronous Fluorescence Fingerprint, Atomic Force Microscopy

\section{Introduction}

Saliva ( $1-1.5 \mathrm{~L} /$ day) is produced from salivary glands by exocrine secretion in the healthy individuals depending on the type of received food, the number of 
meals and water supply. In the case of water insufficiency, production of saliva decreases. The content of saliva is formed by water (99\%) and other compounds (1\%): Glucose, electrolytes (chloride ions, bicarbonates, phosphates, sodium ions, magnesium ions and calcium ions), nitrogen compounds (ammonia, urea) and proteins: enzymes, immunoglobulines, mucosal glycoproteins, albumins, oligopeptides, polypeptides and aquaporins [1].

Saliva possesses several functions such as antibacterial, antimycotic, digestive (hydrolytic enzymes), remineralizing, moisturizing, buffering and neutralizing. Saliva nourishes, mineralizes and protects the tooth enamel against acids from carbohydrate diet which can cause dental caries. The most important amino acid of saliva is arginine $(7-15 \mu \mathrm{mol} / \mathrm{l})$, which neutralizes acids. Acids are result of the conversion of carbohydrates by bacteria. Arginine modifies the structure of the plaques which can not bind to the tooth surface [2]. Certain lactobacilli, actinomycetes, spirochetes and bacteria (Streptococcus gordonii, Streptococcus parasanguinis and Streptococcus miti) have an arginolytic character. These bacteria metabolize free arginine (not bound to peptides and proteins) by arginine deaminase (activity higher in saliva without caries) to ornithine, ammonia and carbon dioxide. The regularity of arginine in the diet increases the number of these microorganisms [3], increases the $\mathrm{pH}$ in the oral cavity, sealing the interior of dentinal tubules, regenerates the dentine in combination with calcium, magnesium, vitamin $\mathrm{K}$ and $\mathrm{D}$ [4] and it removes tooth decay in the early stages by the formation of alkaline metabolites in saliva which increase $\mathrm{pH}$ of saliva [5]. Its protective effect can be disturbed by the decrease of $\mathrm{pH}$. The normal $\mathrm{pH}$ values range between 7 - 7.2 (after stimuli for secretion) and 6 - 6.9 (after meal consumption). Among many influences on the salivary $\mathrm{pH}$, there is a dependence on the type of diet and content of carbohydrates, lipids and proteins. The ketones are the main source of energy in the ketogenic diet which contains $(70 \%)$ lipids, (20\%) proteins and 10\% (carbohydrates). The ketones are produced by the catabolic conversion of lipids. The cereals and legumes are completely absent in the ketogenic diet. The mixed type of diet contains higher (55\%) carbohydrate intake, (30\%) lipids and (15\%) proteins. The low carbohydrate diet contains (25\%) carbohydrates, (40\%) proteins and (35\%) lipids [6]. Vegetarian and vegan diet causes decrease of salivary $\mathrm{pH}$ which manifests as higher occurrence of dental caries [7]. Imbalanced, unilateral and insufficiently mixed diet with inappropriate selection of carbohydrates and improper cleaning of the teeth also lead to dental caries [8]. Carbohydrate are a source of energy but should be consumed in the form of polysaccharides that slowly metabolize and gradually release glucose into the blood [9]. The human organism prefers biocompatible righthanded chiral structure of the unrefined carbohydrates that cells can metabolize. The left-handed chiral structure of artificial sweeteners is nonbiocompatible and it can not be converted by cells, it can be toxic for cells even if it has zero calories [10].

For healthy teeth is essential using an balanced diet which contains optimal 
content of lipids, proteins, minimum carohydrates, all necessary minerals (calcium, magnesium, boron, silicon and others), vitamins B and C, but especially A, $\mathrm{D}, \mathrm{E}, \mathrm{K}$ which increase the correct composition of the pellicle that protects the tooth enamel. The enamel contains selectively permeable microscopic spaces and cracks for certain fluids, pigments, carbohydrates, vitamins and ions for minerals (ions such as calcium, magnesium, iron, silicon, boron and other elements that enhance the crystal structure of enamel depending on their concentration). The enamel hardness increases and the permeability of the enamel decreases in older people [11].

However, there are also foods and beverages which have got not only protective effect but can be used as therapeutic cure, too. From many defensively acting foods, tea, both black and green, has got anti-streptococcal activity due to its catechins. It inhibits the adherence of streptococcal cells, glucosyl transferase and amylase. Cacao, another rich source of catechins, contains the inhibitors of dextransucrase which is enzyme responsible for plaque formation. Coffee, often condemned due to coloring the teeth, is also useful protectant before decays. It has got antibacterial and antiadherence activity which results from the presence of trigonelline, caffeine and chlorogenic acid. Cranberries, even though they have got sweet taste, they have inhibitory effect on the formation of biofilm and adhesion of streptococci. Probiotics, fermented foods, has got anticariogenic effect. It forms the biofilm and competes with plaque bacteria. Additionally, it produces substances which inhibit plaque bacteria [12].

In addition to $\mathrm{pH}$ and bacterial occurance, saliva contains proteins which make this body fluid interesting for diagnostics of various diseases and proteomic analysis. Saliva fluid represents high potential sampling material which contains several proteins which might be examined as possible biomarkers of various oral and systemic diseases [13] [14] [15]. Among more than 1000 detected and identified salivary proteins, the most abundant are $\alpha$-amylase, cystatins, immunoglobulin A, G, M, agglutinin, lysozyme, lactoferrin, peroxidase, lipase, alkaline and acidic phosphatase [16].

The aim of this work is to study the differences in structure of the composition of hard tooth tissues and saliva by different (ketogenic, low carbohydrate, mixed) diet in healthy individuals. The effect of saccharides and the influence of fluids on formation of tooth decay was monitored by evaluating questionnaires by using (descriptive and inductive) statistical methods.

In order to effectively analyse salivary proteome, several methods (synchronous fluorescence fingerprint and atomic force microscopy) are used. The autofluorescence properties of salivary proteins and other substances enable to use the fluorescence analysis. The synchronous fluorescence spectra (SFS) represents characteristic "fingerprint" for saliva of healthy control subjects. SFS is a specific analysis of overall endogenous fluorophores in saliva. During diseases but also other physiological disturbances of homeostasis, the composition of body fluids (saliva) is changed. These results are reflected in differences on SFS and it is 
likely to identify pathological process [17].

\section{Materials and Methods}

\subsection{Experimental}

Health of the teeth of the healthy individuals $(n=263)$ were examined using the questionnaire. Age was stated by 260 respondents with mean ( $x=31,612$ years). The oldest responder was 57, the youngest responder was 19.

Saliva of the healthy individuals with different diet (ketogenic, low carb, mixed) was collected in plastic tubes by flushing an oral cavity with distilled water on the Department of Medical and Clinical Biochemistry, Pavol Jozef Šafárik University in Košice, Faculty of Medicine. Saliva was then centrifugated at 3500 $\mathrm{rpm}$, for 5 minutes, at $\mathrm{t}=4^{\circ} \mathrm{C}$ and frozen at $\mathrm{t}=-80^{\circ} \mathrm{C}$. All clinical investigations were conducted according to the declaration of Helsinki principles. Ethical consent for this study has been given by the institutional committee on human research and is compliant with ethical standards on human experimentation and with the Helsinki declaration. The responders had been instructed about this experiment and signed an informed consent to participate in this biomedical research.

\subsection{Methods}

\subsubsection{Statistical Analysis}

Normality of the data distribution was tested using Anderson-Darling test. All the hypotesis (the effect of water consumption on the frequency of dental caries, influence of sweet consumption on the number of dental caries) was evaluated using Pearson correlation coefficient. For the verification of the hypothesis of difference of the number of dental caries among smokers and unsmokers, Mann-Whitney U-test was used on Minitab Solution 15 software. For the interpretation of the relationships, Cohen scale was used.

\subsubsection{Synchronous Fluorescent Fingerprint}

The samples of saliva were diluted (1:10) with the deionized water immediately before measurment. The intensity of sample autofluorescence were measured in a quartz cuvette $\left(1 \mathrm{~cm}\right.$ width, $3 \mathrm{~cm}^{3}$ volume) by synchronous fluorescence fingerprint (SFF) analysis on Perkin-Elmer Luminiscence Spectrophotometer LS $55, \mathrm{t}=25^{\circ} \mathrm{C}$. Excitation spectra were measured in the wavelength range $\lambda_{\mathrm{ex}}=$ $200-500 \mathrm{~nm}, \Delta=20 \mathrm{~nm}$. The rate of scans was $800 \mathrm{~nm} / \mathrm{s}$, the setting of instrument's excitation slit was $5 \mathrm{~nm}$ and emission slit was $5 \mathrm{~nm}$. The measured results of fluorescence spectra were processed using the graphic WinLab software (version 4, 2001). The resulting three-dimensional spectrum of the SFF was created of 10 simple synchronous scan spectra of saliva measured at various $\Delta \lambda$ located in the area with the increment 10 [18].

\subsubsection{Atomic Force Microscopy}

Exogenous structure of the saliva layers deposited on the glass slides were stu- 
died using atomic force microscopy (AFM). A droplet (10 $\mu$ l) of saliva of the healthy individuals with different diet was pipetted on the cleaned slides. Subsequently, saliva was stretched over the surface of the slide by the method of blood smear and dried at the room temperature without fixation. The samples were analyzed using atomic force microscope Dimension Icon (model FastScan, Bruker). Each surface of the analyzed samples was processed into graphic form by ScanAsyst ${ }^{\text {tw }}$ software.

\section{Results and Discussion}

\subsection{Statistical Analysis}

\subsubsection{Age}

Among 263 responders, the age stated 260 responders with mean $(x=31,612$ years). The oldest responder was 57, the youngest responder was 19 (Figure 1). The most abundant group was made up of the 30 years responders. Anderson-Darling test showed that the data of age did not have normal distribution (Figure 1). For the next calculations, we used the median $(\mathrm{x}=30)$.

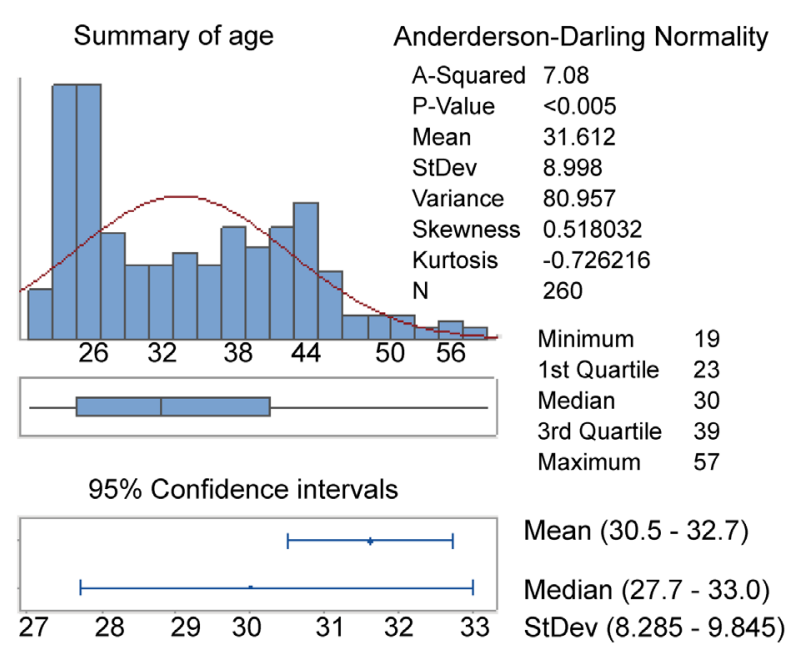

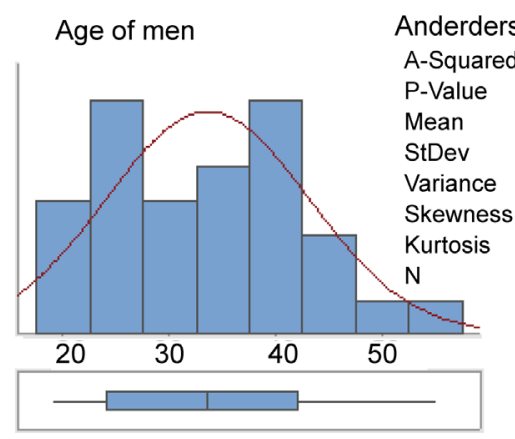

$95 \%$ Confidence intervals

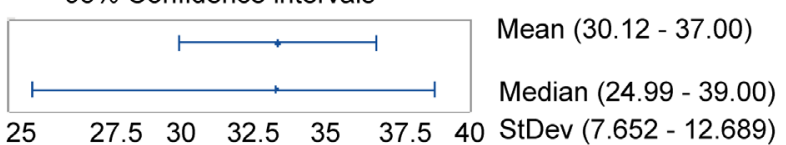

Age of women

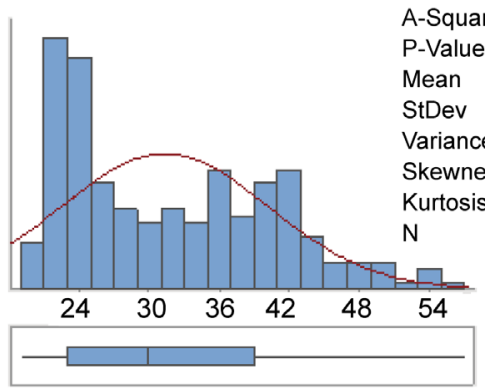

$95 \%$ Confidence intervals

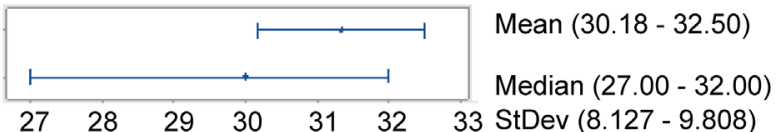

Figure 1. Statistical comparison of respondents' age. 
The correlation between the age and the number of dental caries was small ( $\mathrm{r}$ $=0.208)$. Weak relationship between the age and the number of dental caries could be caused by other variables affecting tooth decay formation. The results confirm the hypotesis that the number of dental caries increse with increasing age $(\mathrm{p}=0.002)$ what is in accordance with other studies [19].

\subsubsection{Fluids Intake}

Almost one half of the responders stated they receive fluids all the time. $44 \%$ of the responders stated they received fluids sometimes, $6 \%$ of the responders stated they received fluids three times a day (Table 1).

The question about the volume of received fluids answered 234 from 263 responders. The average fluids intake was 2 liters/day (Figure 2). Approximately $2 / 3$ of responders receive $1.32-2.69$ liters of fluids. The minimum stated value was 0.3 liters, the maximum stated value was 6 liters. The data about the volume of received fluids did not show normal distribution, the middle value is median (Figure 2).

Significant relationship between fluids intake (frequency, volume) and the number of dental caries did not occur ( $\mathrm{p}=0.737 ; \mathrm{p}=0.896$, respectively). However, intake of plain water might replace sweet beverages consumption, thus, eliminate sugar intake and tooth decays, which was found as appropriate and working strategy [20].

Approximately $2 / 3$ of the responders stated they receive fruit and/or vegetables juices. Two responders did not answer the question (Table 2).

Carbohydrate drink intake showed the smaller cariogenic effect than intake of simple carbohydrates from the solid meals. However, improper selection of the beverages causes insufficient absorption of the essential minerals and vitamins soluble in the water. Just $200 \mathrm{ml}$ of a sweetened beverage could contain $20 \mathrm{~g}$ of sugar. Low $\mathrm{pH}$ and high phosphates of such beverages leads to hyperphosphatemia in the case of long-term consumption which induces hyperparathyroidism with subsequent bone demineralisation [21]. Negative synergic effect could be intensified by low dietary calcium intake. Low $\mathrm{pH}$ and the presence of carbohydrates are favorable for growth of Streptococcus mutans which contributes to tooth decay formation [22].

\subsubsection{Use of Sweetener}

The most prefered sweetener among the responders was white sugar (31\%) followed by brown sugar (15\%), honey (12\%) or other sweetener $(0.4 \%)$ (Figure 3 ).

Table 1. Water intake during a day among the responders.

\begin{tabular}{ccc}
\hline Frequency & Number & $\%$ \\
\hline All the time & 125 & 47.53 \\
Sometimes & 117 & 44.49 \\
Three times a day & 16 & 6.08 \\
Not stated & 5 & 1.90 \\
\hline
\end{tabular}




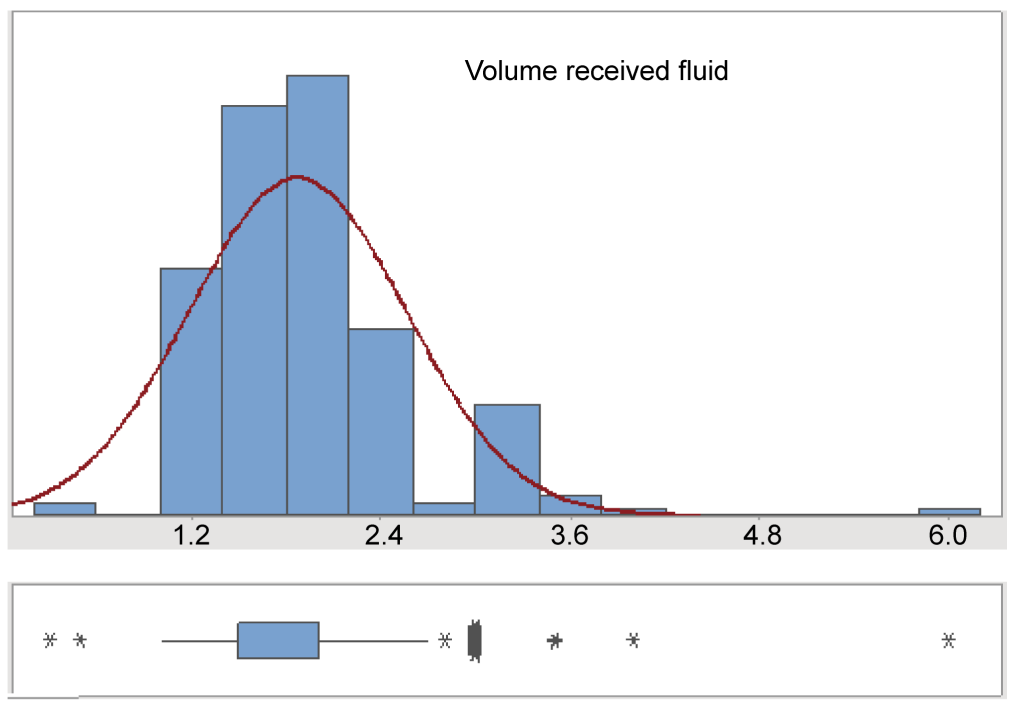

\begin{tabular}{|lc|}
\hline Anderson-Darling & Normality Test \\
A-Squared & 6.34 \\
P-Value & $<0.005$ \\
\hline Mean & 1.8731 \\
StDev & 0.6864 \\
Variance & 0.4712 \\
Skewness & 1.22763 \\
Kurtosis & 4.89718 \\
N & 234 \\
\hline Minimum & 0.3000 \\
1st Quartile & 1.5000 \\
Median & 2.0000 \\
3rd Quartile & 2.0000 \\
Maximum & 6.0000 \\
\hline 95\% Confidence Interval for Mean \\
1.7847 & 1.9615 \\
95\% Confidence Interval for Median & 2.0000 \\
1.6083 & 95\% Confidence Interval for StDev \\
0.6293 & 0.7549 \\
\hline
\end{tabular}

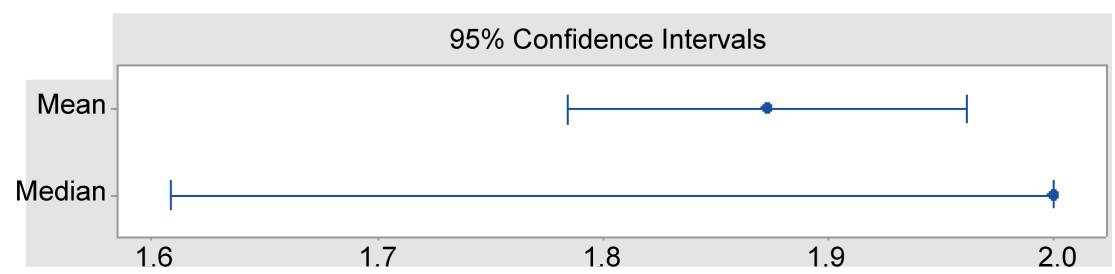

Figure 2. Statistical comparison of volume of fluids received per day among the responders.

Table 2. Fresh juice consumption among the responders.

\begin{tabular}{ccc}
\hline Juice consumption & Number & $\%$ \\
\hline Yes & 164 & 62.36 \\
No & 97 & 36.88 \\
Not stated & 2 & 0.76 \\
\hline
\end{tabular}

The artificial sweeteners have wide range of use including chewing gums, mouthwash and toothpaste because they do not contribute to the dental caries. However, they possess levorotatory chiral structure which our body is not able to process. Whatsmore, their consumption is associated with severe diseases [23] [24].

The role of sugar in the tooth decay formation is overwhelming. Each type of carbohydrate contributes to the dental caries in the different degree. Even though, it is difficult to exactly evaluate the contribution of each carbohydrate on the tooth decay formation due to diversity of human diet, there are such nutritional guidelines which skip carbohydrates almost entirely (ketogenic diet) or eliminates them (low-carb diet) and allow to examine health condition of teeth in long term carbohydrate cut down. 


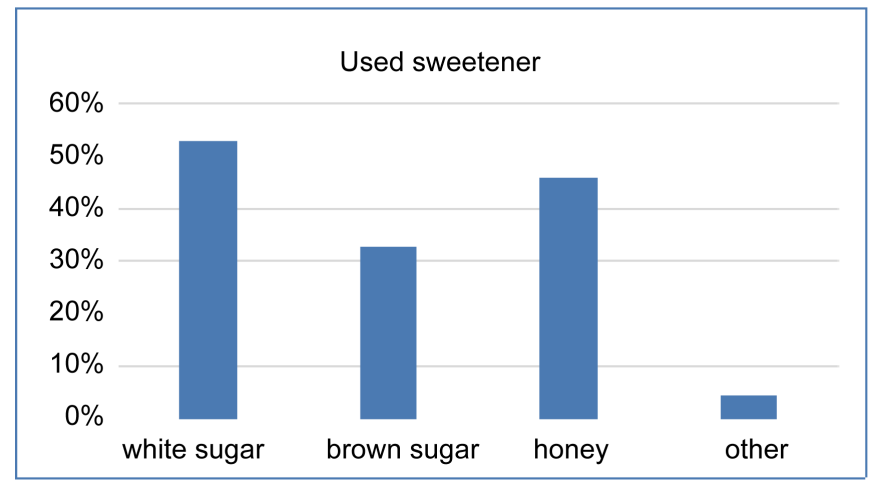

Figure 3. Statistical comparison of the sweeteners used.

\subsubsection{Consumption of Sweets}

The most abundant answer of the responders (39\%) on the consumption of the sweets was at least once a day. On the other hand, 1/4 of the responders (25\%) stated they consume the sweets once per week. Approximately $1 / 5$ of the responders consume the sweets every second day $(20 \%)$ and there were also the responders (14\%) who consume the sweets several times per day. No sweets' consumption stated one respondent $(0.38 \%)$. Our results (Table 3 ) confirm the familiar theorem that the sweets cause teeth damage in the form of decays and enhance the reproduction of harmful bacteria. The effect is already notable even in children [25]. The relationship between sweets consumption and tooth decays is statistically significant $(\mathrm{p}=0.017)$ and large $(\mathrm{r}=0.864)$. Therefore, to limit the sweets intake is the strong prevention before dental caries formation.

\subsection{Experimental Analysis of Saliva of Healthy Individuals with Different Diets}

\subsubsection{Synchronous Fluorescence Fingerprint (SFF) of Saliva}

SFS of saliva differs among healthy individuals with different diet (Figure 4). The highest fluorescence intensity $(\mathrm{F}=795)$ showed low carb diet saliva. Many factors impact the fluorescence intensity, thus, it is not a trivial task to decode the exact reason. We suggest the high fluorescence could reflect the vitality of saliva and higher protein intake, too, in comparison with mixed $(\mathrm{F}=573)$ and ketogenic diet $(F=435)$ (Figure 5). The maximum peak was present at $\lambda_{\mathrm{ex}}=276$ $\mathrm{nm} / \Delta \lambda=70 \mathrm{~nm}$ in all cases.

Saliva, with its immense number of proteins and other substances, has the ability to reflect the changes of the inside homeostasis [26]. Therefore, the bias could be present and caused by other lifestyle variables such as a sport on regular basis, smoking, stress, etc. Furthermore, salivary fluorescence with specific excitation light wavelength could be used for more specific evaluation of the health of the oral cavity [27].

\subsubsection{Atomic Force Microscopy (AFM) of Saliva}

Salivary surfaces studied by AFM revealed characteristic structures (crystals) according to the diet (Figure 6). Low carb diet saliva did not show the presence 
Table 3. Consumption of sweets.

\begin{tabular}{ccc}
\hline Frequency & Number & $\%$ \\
\hline Several times a day & 37 & 14.07 \\
Once a day & 105 & 39.92 \\
Every second day & 52 & 19.77 \\
Once per week and less & 65 & 24.71 \\
No consumption of sweets & 3 & 1.14 \\
Not stated & 1 & 0.38 \\
\hline
\end{tabular}
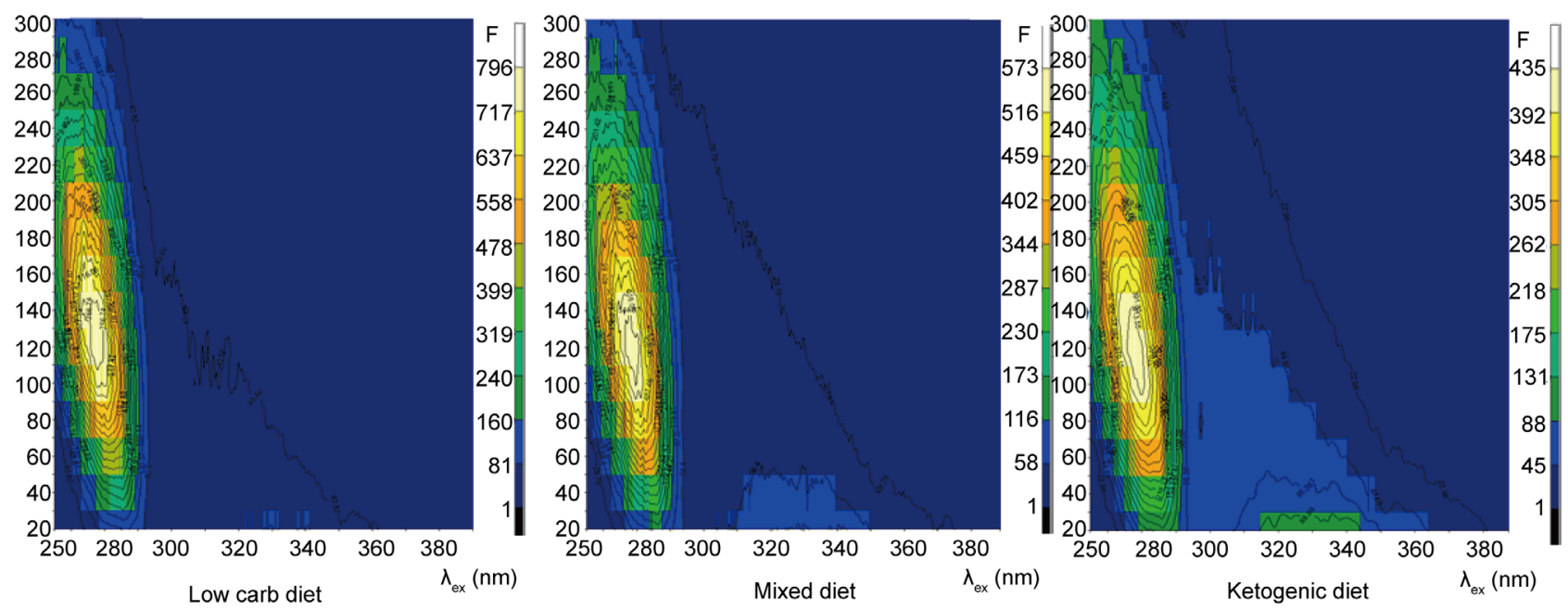

Figure 4. The synchronous fluorescence fingerprint (contour maps) of saliva of healthy subjects with low carb, mixed, ketogenic diet. The maximum peak is present at $\lambda_{\mathrm{ex}}=276 \mathrm{~nm}$ (axis x) $/ \Delta \lambda=70 \mathrm{~nm}$ (axis y) and the fluorescence intensity is $\mathrm{F}=795, \mathrm{~F}=573$, $\mathrm{F}=435$ (axis z), respectively.

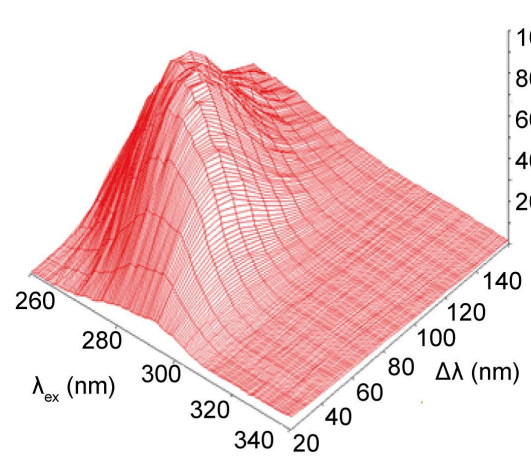

Low carb diet

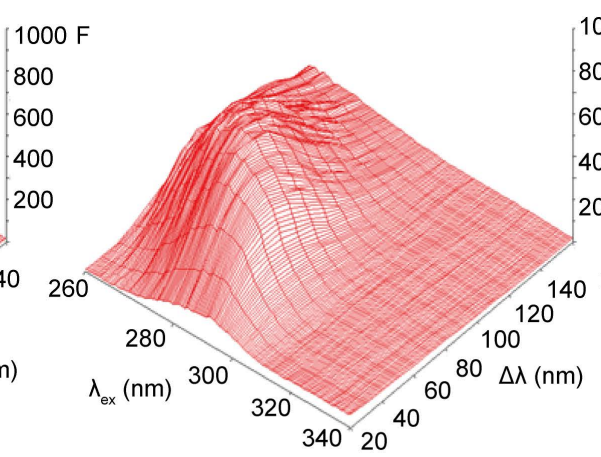

Mixed diet

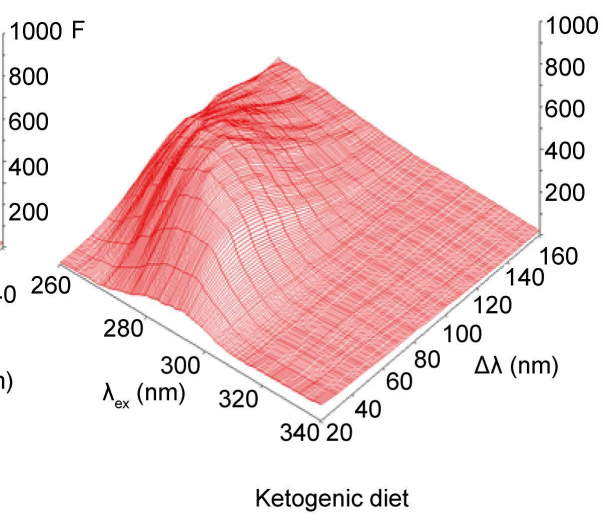

Ketogenic diet

Figure 5. The synchronous fluorescence fingerprint of saliva of healthy subjects with low carb, mixed, ketogenic diet.

of crystals but two types of regular round-shaped particles: minor particles (20 $\mathrm{nm}$ ) and major particles (164 - $200 \mathrm{~nm}$ ) with surafce roughness $9.31 \mathrm{~nm}$. Mixed diet showed the presence of globules with different size $(70-150 \mathrm{~nm})$ and crystals $(400-1000 \mathrm{~nm})$. Surface roughness was increased $(25.2 \mathrm{~nm})$ in comparison with low carb diet. Ketogenic diet saliva showed the biggest modifications in the 

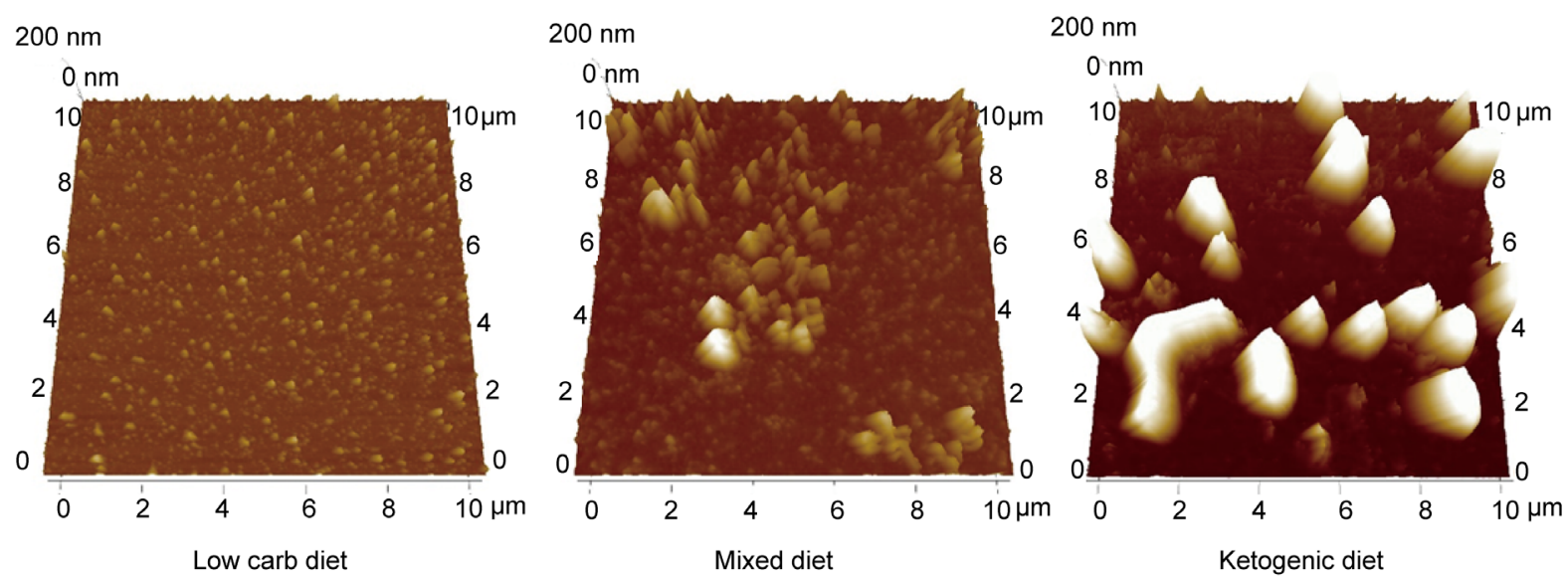

Figure 6. Atomic force microscopy of the surfaces of the saliva of healthy subjects with low carb, mixed, ketogenic diet.

form of large crystals (1000 - $2000 \mathrm{~nm})$. The globule particles $(100-200 \mathrm{~nm})$ occured, as well, with the highest roughness $(84.9 \mathrm{~nm})$. Comparison of the saliva surfaces could contribute to the evaluation of the saliva vitality and overall health condition, which diet affect in the significant way. Our result indicates the low carb diet as the most appropriate healthy option. However, it would be incorrect to neglect also other lifestyle factors which have the influence on overall health, hence, it could be reflected in the salivary surface.

\section{Conclusion}

This experimental work studied saliva of healthy subjects with different diet. It can show the benefits of specific type of diet and utilisation of novel techniques (synchronous fluorescence fingerprint, atomic force microscopy) for analysis of saliva. Saliva analysis could control the health of oral cavity which allows an early prevention against dental caries. The highest total fluorescence intensity showed saliva of low carb diet followed by mixed diet and the lowest fluorescence intensity showed ketogenic diet. The analysis of salivary surface showed the same tendency. The most ordered particles were revealed on the surface of saliva of low carb diet. Mixed and ketogenic diet revealed the presence of crystals and particles with various size. Our results confirmed the sense of different opinions about the impact of ketogenic diet on the overall health together with the opinion that the mixed diet contains the high amount of carbohydrates that showed harmful effect on the teeth health. The various factors including type of diet as well as amount of sugar in diet can modify the salivary surface structure and can change the salivary endogenous fluorophores which can be detected by fluorescence spectroscopy. Further studies are needed to investigate the effects of ketogenic and low-carbohydrate diets on the salivary structure.

\section{Acknowledgements}

This work was supported by the ERDF EU grant under contract No. ITMS26220120047 and VEGA-1/0409/15. 


\section{References}

[1] Wang, Q., Yu, Q., Lin, Q. and Duan, Y. (2015) Emerging Salivary Biomarkers by Mass Spectrometry. Clinica Chimica Acta, 483, 214-221. https://doi.org/10.1016/j.cca.2014.08.037

[2] Kolderman, E., Bettampadi, D., Samarian, D., Dowd, S.E., Foxman, B., Jakubovics, N.S. and Rickard, A.H. (2015) L-Arginine Destabilizes Oral Multi-Species Biofilm Communities Developed in Human Saliva. PloS One, 10, e0121835. https://doi.org/10.1371/journal.pone.0121835

[3] Nascimento, M.M., Browngardt, C., Xiaohui, X., Klepac-Ceraj, V., Paster, B.J. and Burne, R.A. (2014) The Effect of Arginine on Oral Biofilm Communities. Molecular Oral Biology, 29, 45-54. https://doi.org/10.1111/omi.12044

[4] Petrou, I., Heu, R., Stranick, M., Lavender, S., Zaidel, L., Cummins, D., Sullivan, R.J., Hsueh, C. and Gimzewski, J.K. (2009) A Breaktrough Therapy for Dentin Hypersensitivity: How Dental Products Contain 8\% Arginine and Calcium Carbonate Work to Deliver Effective Relief of Sensitive Teeth. Journal of Clinical Dentistry, 20, 23-31.

[5] Tada, A., Nakayama-Imaohji, H., Yamasaki, H., Hasibul, K., Yoneda, S., Uchida, K., Nariya, H., Suzuki, M., Miyake, M. and Kuwahara, T. (2016) Cleansing Effect of Acidic L-Arginine on Human Oral Biofilm. BMC Oral Health, 16, 40. https://doi.org/10.1186/s12903-016-0194-Z

[6] Klonoff, C.D. (2009) The Beneficial Effects of a Paleolithic Diet on Type 2 Diabetes and Other Risk Factors for Cardiovascular Disease. Journal of Diabetes Science and Technology, 3, 1229-1232. https://doi.org/10.1177/193229680900300601

[7] Zotti, F., Laffranchi, F., Fontana, P., Dalessandri, D., Bonetti, S. (2014) Effects of Fluorotherapy on Oral Changes Caused by a Vegan Diet. Minerva Stomatologica, 63, 179-188.

[8] Hujoel, P.P. and Lingström, P. (2017) Nutrition, Dental Caries and Periodontal Disease: A Narrative Review. Journal of Clinical Periodontology, 44, 79-84. https://doi.org/10.1111/jcpe.12672

[9] Paglia, L., Scaglioni, S., Torchia, V., De Cosmi, V., Moretti, M., Marzo, G. and Giuca, R. (2016) Familial and Dietary Risk Factors in Early Childhood Caries. European Journal of Paediatric Dentistry, 17, 93-99.

[10] Gulube, Z. and Patel, M. (2016) Effect of Punica granatum on the Virulence Factors of Cariogenic Bacteria Streptococcus mutans. Microbial Pathogenesis, 98, 45-49.

[11] Dorvee, J.R., Gerkowicz, L., Bahmanyar, S., Deymier-Black, A. and Veis, A. (2016) Chondroitin Sulfate Is Involved in the Hypercalcification of the Organic Matrix of Bovine Peritubular Dentin Research. Archives of Oral Biology, 62, 93-100.

[12] Venkatesan, K. and Ranjan, M. (2015) Beat the Decay in a Foody Fashion. International Journal of Pharma and Bio Sciences, 6, 343-348.

[13] Souza, M.M.D., de Paula, F.M., Hsieh, R., Cristina, M., Macedo, M.A., Corral, M.A. and Nunez, T.B. (2017) Could Mucin 16 and Colony-Stimulating Factor 2-Receptor Beta Possible Graft versus Host Disease Biomarkers? Medical Hypothesis, 100, 89-93.

[14] Aqrawi, L.A., Galtung, H.K., Vestad, B., Øvstebø, R., Thiede, B., Rusthen, S., Young, A., Guerreiro, E.M., Utheim, T.P., Chen, X., Utheim, Ø.A., Palm, Ø. and Jensen, J.L. (2017) Identification of Potential Saliva and Tear Biomarkers in Primary Sjögren's Syndrome, Utilising the Extraction of Extracellular Vesicles and Proteomics Analysis. Arthrisis Research and Therapy, 19, 14. 
https://doi.org/10.1186/s13075-017-1228-X

[15] Bottoni, U., Tiriolo, R., Pullano, S.A., Dastoli, S., Amoruso, G.F., Nisticò, S.P. and Fiorillo, A.S. (2016) Infrared Saliva Analysis of Psoriatic and Diabetic Patients: Similarities in Protein Components. IEEE Transactions on Biomedical Engineering, 63, 379-384. https://doi.org/10.1109/TBME.2015.2458967

[16] Loo, J.A., Yan, W., Ramachandran, P. and Wong, D.T. (2010) Comparative Human Salivary and Plasma Proteomes. Journal of Dental Research, 89, 1016-1023. https://doi.org/10.1177/0022034510380414

[17] Tomečková, V., Komanický, V., Kakoush, M., Krajčíková, K., Glinská, G., Široká, M., Pundová, L., Samuely, T., Hložná, D. and Lotnyk, D. (2016) Monitoring of Heart Ischemia in Blood Serum. Spectral Analysis Review, 4, 11-22. https://doi.org/10.4236/sar.2016.42002

[18] Berezin, M.Y. and Achilefu, S. (2010) Fluorescenc Lifetime Measurments and Biological Imaging. Chemical Reviews, 110, 2641-2684. https://doi.org/10.1021/cr900343z

[19] Gil-Montoya, J.A., de Mello, A.L.F., Barrios, R., Gonzalez-Moles, M.A. and Bravo, M. (2015) Oral Health in the Elderly Patients and Its Impact on General Well-Being: A Nonsystematic Review. Clinical Interventions in Ageing, 10, 461-467. https://doi.org/10.2147/CIA.S54630

[20] Sharma, M., Catalano, H.P., Nahar, V.K., Lingam, V.C., Johnson, P. and Ford, M.A. (2017) Applying Multi-Theory Model (MTM) of Health Behavior Change to Predict Water Conumption Instead of Sugar-Sweeted Beverages. Journal of Research in Health Sciences, 17, e00370.

[21] Shutto, Y., Shimada, M., Kitajima, M., Yamabe, H., Saitoh, Y., Saitoh, H. and Razzaque, M.S. (2013) Inadequate Awareness among Chronic Kidney Disease Patients Regarding Food and Drinks Containing Artificially Added Phosphate. PLoS ONE, 8, 78660. https://doi.org/10.1371/journal.pone.0078660

[22] Krzyściak, W., Jurczak, A., Kościelniak, D., Bystrowska, B. and Skalniak, A. (2013) The Virulence of Streptococcus mutans and the Ability to Form Biofilms. European Journal of Clinical Microbiology and Infectious Diseases, 33, 499-515. https://doi.org/10.1007/s10096-013-1993-7

[23] Pase, M.P., Himali, J.J., Beiser, A.S., Aparicio, H.J., Satizabal, C.L., Vasan, R.S., Seshadri, S. and Jacques, P.F. (2017) Sugar- and Artificially Sweetened Beverages and the Risk of Incident Stroke and Dementia. Stroke. http://stroke.ahajournals.org/content/early/2017/04/20/STROKEAHA.116.016027

[24] Marivonich, M., Galli, C.L., Bosetti, C., Gallus, S. and La Vecchia, C. (2013) Aspartame, Low-Calorie Sweeteners and Diseases: Regulatory Safety and Epidemiological Issues. Food and Chemical Toxicology, 60, 109-115.

[25] Schwendicke, F., Doost, F., Hopfenmüller, W., Meyer-Lueckel, H. and Paris, S. (2015) Dental Caries, Fluorosis, and Oral Health Behavior of Children from Herat, Afghanistan. Community Dentistry and Oral Epidemiology, 43, 521-531. https://doi.org/10.1111/cdoe.12177

[26] Bozovic, D., Racic, M. and Ivkovic, N. (2013) Salivary Cortisol Levels as a Biological Marker of Stress Reaction. Medical Archives, 67, 374-377. https://doi.org/10.5455/medarh.2013.67.374-377

[27] Volgenant, C.M.C., Hoogenkamp, M.A., Krom, B.P., Janus, M.M., Ten Cate, J.M., De Soet, J.J., Crielaard, W. and Van der Veen, M.H. (2016) Red and Green Fluorescence from Oral Biofilms. PLoS ONE, 11, e0168428. https://doi.org/10.1371/journal.pone.0168428 